\title{
A social work study on the effect of spiritual intelligence and psychological capital on sense of vitality
}

\author{
Zahra Mahmoudi Kataki ${ }^{a^{*}}$, Fatemeh Rezaei ${ }^{\mathrm{b}}$ and Yousef Gorji ${ }^{\mathrm{c}}$
}

${ }^{a}$ MS Student, Counseling Department, Islamic Azad University of Khomeinishahr, Khomeinishahr Branch, Daneshjou Blvd, Iran

${ }^{b}$ Assistant Professor, Counseling Department, Islamic Azad University of Khomeinishahr, Khomeinishahr Branch, Daneshjou Blvd, Iran

${ }^{c}$ Assistant Professor, Counseling Department, Islamic Azad University of Khomeinishahr, Khomeinishahr Branch, Daneshjou Blvd, Iran

\section{H R O N I C L E}

Article history:

Received January 20, 2013

Received in revised format

2 May 2013

Accepted 20 May 2013

Available online

May 232013

Keywords:

Spiritual intelligence

Psychological capital

Sense of vitality

\begin{abstract}
A B S T R A C T
This paper performs a social work study on the effect of spiritual intelligence and psychological capital on sense of vitality among elementary school teachers in two regions of city of Esfahan, Iran. The proposed study uses three standard questionnaires of psychological capital questionnaire (PCQ), Spiritual Intelligence Self-Report Inventory (SISRI-24) and sense of vitality and distributes them among 263 teachers selected, randomly. The results of the survey have been analyzed using Pearson correlation as well as stepwise regression techniques. The results of the Pearson correlation tests have shown that the components of psychological capital questionnaire and spiritual intelligence have meaningful relationship with sense of vitality $(\mathrm{P}<0.01)$. The survey have also confirmed that psychological capital and spiritual intelligence have meaningful effects on teachers' personal characteristics.
\end{abstract}

\section{Introduction}

During the past few decades, we have seen extensive discussion about spirituality and its effects on human life (Diener et al., 2003). Halama and strizenec (2004) discussed the nature of intelligence associated with the existential and spiritual dimension of individuals. They investigated the relationships between spirituality and thinking and reviewed the most commonly known theories of spiritual intelligence. They also discussed about the lack of empirical investigation in this area and explained possible measurements of spiritual intelligence through specific subscales of spirituality measures. They started from existential thinking in psychology to conceptualize existential intelligence. They reported that existential intelligence could be recognized as a capability to detect and to realize sufficient life meaning. Hughes (2008) presented an empirical investigation on relationship between sense of humor and positive psychological capacities. 
Faribors et al. (2010) studied the relationship between Spiritual Intelligence and Happiness as well as the relationship between Spiritual Intelligence, Happiness and demographic characteristics of the respondents among nurses in two hospitals in Bushehr, Iran. Their results demonstrated that there was a significant relationship between the Spiritual intelligence and Happiness. They also stated that all nurses' demographic characteristics had significant relationship with spiritual intelligence and happiness. Youssef and Luthans (2005) investigated the impact of a positive organizational behavior approach on ethical performance. Youssef and Luthans (2007) performed an investigation on the effect of selected positive psychological resource capacities of hope, optimism, and resilience have on desired work-related employee outcomes. Their findings generally supported that employees' positive psychological resource capacities was associated with hope and optimism.

Ryan and Frederick (1997) examined subjective vitality, a positive feeling of aliveness and energy, in various studies. They explained that subjective vitality could reflect organismic well-being with both psychological and somatic factors, which influence the energy available to the self. The relationship was demonstrated between subjective vitality and several indexes of psychological well-being. Vitality was also demonstrated to be lower in people with chronic pain compared with matched controls, especially those who perceive their pain to be disabling or frightening. They concentrated on the phenomenological salience of personal energy and its relationship with physical and psychological well-being. Ryan and Deci (2000), in other word, investigated on self-determination theory and the facilitation of intrinsic motivation, social development, and well-being. Ryan et al. (1997) began by looking at the origins of the organizational viewpoint in early debates within the field of biology between vitalists and reductionists and then considered human autonomy as an evolved behavioral, developmental, and experiential phenomenon that operates at both neurobiological and psychological levels. They argued that disturbances of autonomy, which had both biological and psychological etiologies, were central to many forms of psychopathology and social alienation.

Luthans et al. (2006) presented a micro-intervention to develop psychological capital (PsyCap), which is drawn from hope, optimism, efficacy, and resiliency development. PsyCap Intervention (PCI) was described to have preliminary support for not only increasing participants' PsyCap, but also financial effect and high return on investment. Luthans et al. (2007) performed two studies to study how hope, resilience, optimism, and efficacy individually and as a composite higher-order factor could forecast work performance and satisfaction. They provided some psychometric support for a new survey measure designed to assess each of these 4 aspects, as well as a composite factor. They also provided a substantial positive relationship regarding the composite of these 4 aspects with performance and satisfaction. Arbabisarjou et al. (2013) investigated the relationship between various kinds of the intelligence and student achievement in University of Isfahan. They studied the relationship among emotional intelligence and spiritual intelligence with student achievement. They reported that it was possible to introduce a model, which explain student's achievement based on the emotional and spiritual intelligences.

\section{The proposed study}

In this paper, we present a social work study on the effect of spiritual intelligence and psychological capital on sense of vitality among elementary school teachers in two regions of city of Esfahan, Iran. The proposed study uses three standard questionnaires of psychological capital questionnaire (PCQ), Spiritual Intelligence Self-Report Inventory (SISRI-24) and sense of vitality and distributes them among teachers selected, randomly. The sample size is calculated as follows,

$$
n=\frac{N \times z_{\alpha / 2}^{2} \times p \times q}{\varepsilon^{2} \times(N-1)+z_{\alpha / 2}^{2} \times p \times q},
$$


where $N$ is the population size, $p=1-q$ represents the yes/no categories, $z_{\alpha / 2}$ is CDF of normal distribution and finally $\varepsilon$ is the error term. Since we have $p=0.5, z_{\alpha / 2}=1.96$ and $N=840$, the number of sample size is calculated as $n=263$. In our study, there were 40 men and 800 women and we selected 13 men and 250 women as sample size. In our survey, $15.6 \%$ of the surveyed people were single, $77.9 \%$ of them were married and the remaining $6.5 \%$ did not specify anything about their marital status. Fig. 1 shows some of their personal characteristics of the surveyed people.

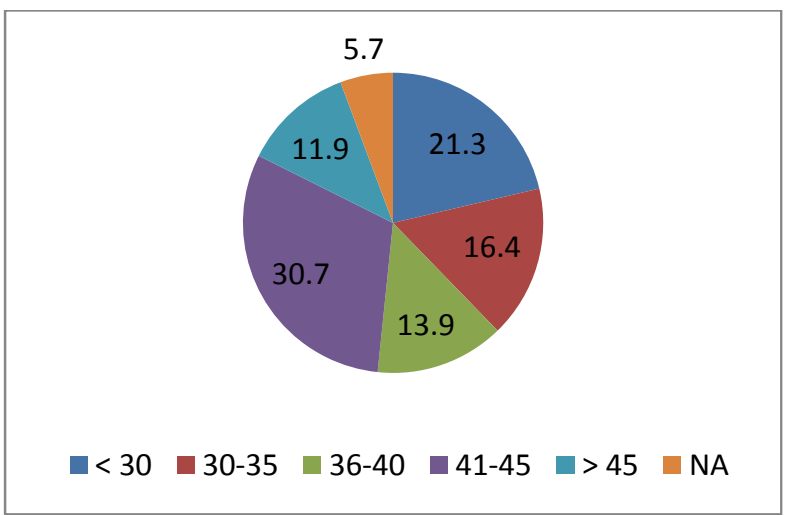

Participants' age

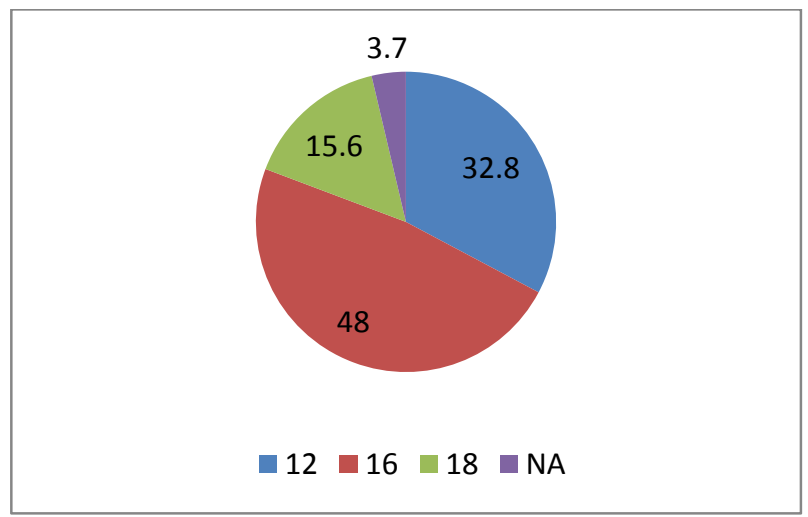

Participants' years of education

Fig. 1. Personal characteristics of the participants

There were three questionnaires associated with this study: The first questionnaire is Psychological Capital Questionnaires (PCQ) developed by Luthans et al. (2007), which measures hope, resilience, optimism, and efficacy individually and it consists of 24 questions. All questions were designed in terms of 6 Likert scale from completely disagree to completely agree and Cronbach alpha was calculated as 0.87 . Table 1 demonstrates some basic statistics on the components of this questionnaire.

\section{Table 1}

The results of some basic statistics on Psychological Capital Questionnaires (PCQ)

\begin{tabular}{lcccccc}
\hline Component & Mean & Std. Dev. & Var. & Median & Min & Max \\
\hline Efficacy individually & 21.22 & 4.50 & 20.29 & 20 & 14 & 28 \\
Hope & 20.73 & 6 & 36.07 & 20 & 12 & 29 \\
Optimism & 21.41 & 4.49 & 20.18 & 21 & 14 & 28 \\
Resilience & 21.36 & 4.60 & 21.21 & 22 & 12 & 28 \\
\hline
\end{tabular}

The second questionnaire is associated with Spiritual Intelligence Self-Report Inventory (SISRI-24) questionnaire developed by King (2007, 2008, 2009). The questionnaire consists of four components including "critical existential thinking”, "Personal meaning production”, “Transcendental awareness" and "Conscious status expansion" and they contain 5, 7, 5 and 7 questions, respectively. Cronbach alpha was calculated as 0.87 , which is well above the desirable limit. Table 2 demonstrates some basic statistics associated with our survey.

Table 2

The results of some basic statistics on Spiritual Intelligence Self-Report Inventory (SISRI-24)

\begin{tabular}{lcccccc}
\hline Component & Mean & Std. Dev. & Var. & Median & Min & Max \\
\hline Critical existential thinking & 23.82 & 4.75 & 22.26 & 24 & 14 & 32 \\
Personal meaning production & 22.74 & 4.76 & 22.73 & 23 & 12 & 30 \\
Transcendental awareness & 19.44 & 4.35 & 18.91 & 20 & 12 & 28 \\
Conscious status expansion & 19.41 & 5.63 & 31.67 & 20 & 13 & 30 \\
\hline
\end{tabular}


1562

Finally, our last survey questionnaire is associated with vitality and it is based on the work accomplished by Deci and Ryan (1995) and it is designed based on 7 scale Likert scale. In our survey, Cronbach alpha has been calculated as 0.85 , which is well above the reference level of 0.78. Table 3 shows some basic statistics associated with vitality.

Table 3

The results of some basic statistics vitality

\begin{tabular}{lcccccc}
\hline Component & Mean & Std. Dev. & Var. & Median & Min & Max \\
\hline Vitality & 37.07 & 6.37 & 40.63 & 40 & 25 & 45 \\
\hline
\end{tabular}

\section{The results}

In this section, we present details of our findings on testing various hypotheses associated with our survey.

\subsection{First hypothesis}

The first hypothesis is associated with the relationship between different components of the survey. Table 4 demonstrates the results of Pearson correlation test among various components of the survey.

Table 4

The results of Pearson correlation test

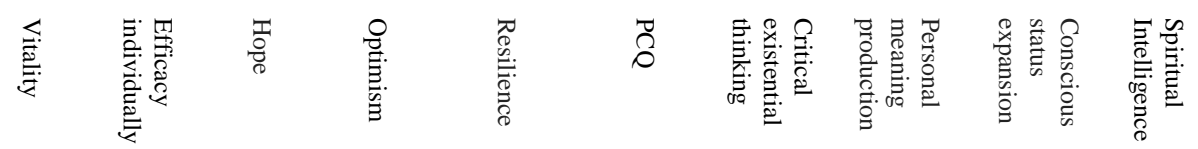

\begin{tabular}{|c|c|c|c|c|c|c|c|c|c|c|}
\hline Vitality & 1 & & & & & & & & & \\
\hline Efficacy individually & 0.494 & 1 & & & & & & & & \\
\hline Hope & 0.556 & 0.427 & 1 & & & & & & & \\
\hline Optimism & 0.726 & 0.292 & 0.729 & 1 & & & & & & \\
\hline Resilience & 0.568 & 0.228 & 0.436 & 0.566 & 1 & & & & & \\
\hline PCQ & 0.756 & 0.623 & 0.873 & 0.845 & 0.713 & 1 & & & & \\
\hline Critical existential thinking & 0.418 & 0.34 & 0.527 & 0.448 & 0.185 & 0.5 & 1 & & & \\
\hline Personal meaning production & 0.375 & 0.261 & 0.271 & 0.479 & 0.463 & 0.468 & 0.194 & 1 & & \\
\hline Transcendental awareness & 0.197 & 0.245 & 0.33 & 0.350 & -0.134 & 0.267 & 0.339 & 0.72 & 1 & \\
\hline Conscious status expansion & 0.18 & 0.46 & 0.21 & 0.277 & 0.35 & 0.115 & 0.299 & 0.51 & 0.397 & 1 \\
\hline Spiritual Intelligence & 0.416 & 0.308 & 0.394 & 0.552 & 0.199 & 0.472 & 0.65 & 0.653 & 0.629 & 0.825 \\
\hline
\end{tabular}

The numbers, which are shown on Table 4 in bold colors represent strong correlation among various components where the level of significance is one percent. Therefore, the first hypothesis of this survey has been confirmed and we can conclude that there are strong relationship between the components of three questionnaires.

\subsection{The second hypothesis}

The second hypothesis of this survey considers the relationship between vitality as dependent variable and PCQ components including efficiency individually, hope, optimism and resilience. We have performed stepwise regression analysis and the results are as follows,

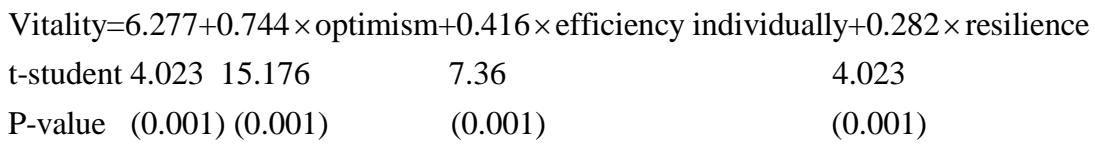

As we can observe from the results of the regression analysis, there are meaningful relationship between three components of PCQ and vitality, which confirms the second hypothesis of the survey. 


\subsection{The third hypothesis}

The third hypothesis of this survey considers the relationship between vitality as dependent variable and Spiritual Intelligence components including critical existential thinking (CET), personal meaning production (PMP), transcendental awareness and conscious status expansion. We have performed stepwise regression analysis and the results are as follows,

\begin{tabular}{|c|c|c|}
\hline t-student 12.453 & 7.4163 & 7.221 \\
\hline P-value (0.001) & $(0.001)$ & $(0.001)$ \\
\hline
\end{tabular}

As we can observe from the results of the regression analysis, there are meaningful relationship between three components of Spiritual Intelligence and vitality, which confirms the third hypothesis of the survey.

\subsection{The fourth hypothesis}

The last hypothesis of this survey investigates the relationship between age and vitality, spiritual intelligence and psychological capital. The implementation of Pearson correlation test indicates that there are some positive and meaningful relationship between age and three components. The correlations for vitality, spiritual intelligence and psychological capital are 0.76, 0.34 and 0.45 , respectively.

\section{Conclusion}

In this paper, we have presented an empirical investigation to study the relationship between vitality as independent variables and spiritual intelligence and psychological capital as well as some personal characteristics of some teachers in city of Esfahan, Iran. The results of our survey have concluded that there were some meaningful and positive relationship between vitality and some components of independent variables. In other words, our survey has indicated that vitality could be described as a function of efficiency individually, optimism and resilience. In addition, vitality could be described as a function of critical existential thinking and personal meaning production. Finally, age influenced vitality, spiritual intelligence and psychological capital, significantly.

\section{Acknowledgment}

The authors would like to thank anonymous referees for constructive comments on earlier version of this work. We would like to acknowledge for the help of people how cordially participated in our survey.

\section{References}

Arbabisarjou, A., Raghib, M. S., Moayed, N., \& Rezazadeh, S. S. (2013). Relationship between Different Types of Intelligence and Student Achievement. Life Science Journal, 10(7s), 128-133.

Deci, E. L., \& Ryan, R. M. (1995). Human autonomy: The basis for true self-esteem.

Diener, E., Napa Scollon, C., \& Lucas, R. E. (2003). The evolving concept of subjective well-being: The multifaceted nature of happiness. Advances in cell aging and gerontology, 15, 187-219.

Faribors, B., Fatemeh, A., \& Hamidreza, H. (2010). The relationship between nurses' spiritual intelligence and happiness in Iran. Procedia-Social and Behavioral Sciences, 5, 1556-1561.

Halama, P., \& strizenec, M. ( 2004). Spiritual, existential or both? Theoretical considerations on the nature of higher intelligence. Studia Psychologica, 43(3), 239- 250. 
Hughes, L. W. (2008). A correlational study of the relationship between sense of humor and positive psychological capacities. Economice and Besiness Jouranal, 1, 46-53.

King D. (2007). The Spiritual Intelligence Project. [dissertation].In press.

King, D. B. (2008). Rethinking claims of spiritual intelligence: A definition, model, and measure. Trent University (Canada).

King, D. B., \& Teresa, L. D. (2009). A viable model and self-report measure of spiritual intelligence. International Journal, 28.

Luthans, F., Avey, J. B., Avolio, B. J., Norman, S. M., \& Combs, G. M. (2006). Psychological capital development: toward a micro-intervention. Journal of Organizational Behavior, 27(3), 387-393.

Luthans, F., Avolio, B. J., Avey, J. B., \& Norman, S. M. (2007). Positive psychological capital: Measurement and relationship with performance and satisfaction. Personnel Psychology, 60(3), 541-572.

Ryan, R. M., Kuhl, J., \& Deci, E. L. (1997). Nature and autonomy: An organizational view of social and neurobiological aspects of self-regulation in behavior and development. Development and psychopathology, 9(04), 701-728.

Ryan, R. M., \& Frederick, C. (1997). On energy, personality, and health: Subjective vitality as a dynamic reflection of well-being. Journal of personality, 65(3), 529-565.

Ryan, R. M., \& Deci, E. L. (2000). Self-determination theory and the facilitation of intrinsic motivation, social development, and well-being. American psychologist, 55(1), 68-78.

Youssef, C., \& Luthans, F. (2005). A positive organizational behavior approach to ethical performance. Positive psychology in business ethics and corporate social responsibility, 1-22.

Youssef, C. M., \& Luthans, F. (2007). Positive organizational behavior in the workplace: The impact of hope, optimism, and resilience. Journal of Management, 33(5), 774-800.

Zohar, D (2000). SQ: Spiritual intelligence: the ultimate intelligence. New York, NY, USA: ISBN: 074546762.

Zohar, D., \& Marshall, I. (2000). SQ: Connecting with our spiritual intelligence. Bloomsbury USA. 